\title{
Effect of Six Months of Aerobic Exercise on Serum Levels of Insulin, Growth Hormone and Insulin-Like Growth Hormone 1 in Sedentary Obese Women
}

\author{
Mahtab Moazami (PhD) \\ Department of Exercise Physiology, \\ Faculty of Physical Education and \\ Sport Science, Ferdowsi University of \\ Mashhad, Mashhad, Iran \\ Babisan Askari (PhD) \\ Department of Physical Education and \\ Sport Science, Islamic Azad \\ University, Qaemshahr Branch, \\ Qaemshahr, Iran \\ Corresponding author: Dr Mahtab \\ Moazami \\ Tel: +989153156705 \\ Email: mahtab.moazami@gmail.com \\ Address: Faculty of Physical \\ Education and Sport Sciences, \\ Ferdowsi University of Mashhad, \\ Mashhad. Iran \\ Received : 04 May 2015 \\ Revised: 01 Jun 2015 \\ Accepted: 02 Jun 2015 \\ Mahtab Moazami https://orcid.org/0000-0001-8354- \\ 2662 \\ Babisan Askari 0000-0002-9411-8549
}

\section{ABSTRACT}

Background and Objectives: Inactivity, obesity and hormone disorders can lead to various diseases in obese and non-athletic individuals. The objective of this study was to investigate effects of six months of aerobic exercise on serum levels of insulin, growth hormone (GH) and insulin-like growth hormone 1 (IGF-l) in sedentary obese women.

Methods: In this quasi-experimental study, 15 inactive, obese (body mass index $>30$ ) women aged 37-47 years were selected from employees of the Ferdowsi University in Mashhad (Iran), via purposive and available sampling. The participants were randomly divided into an experimental group $(n=10)$ and a control $(n=5)$ group. The experimental group performed 60 minutes of aerobic exercise at $55-65 \%$ of heart rate reserve, three sessions a week, for six months. Serum GH, IGF-1 and insulin levels were measured in both groups before the first training session and after the last training session. The Shapiro-Wilk test and the Levene's test were used to assess normal distribution of data and homogeneity of variance, respectively. Independent and dependent t-tests were used to compare betweengroup and within-group differences at significance of 0.05 . All statistical analyses were performed using the SPSS software (version 18).

Results: Serum concentrations of IGF-1 and insulin reduced significantly following the six-month aerobic exercise program. In addition, the exercise training caused an insignificant increase in GH levels.

Conclusion: 0ur proposed aerobic exercise protocol significantly reduces IGF-1 level, which is closely related to the incidence of atherosclerosis, breast cancer, and colon cancer. The significant decline in insulin secretion following the six-month aerobic exercise program may provide more amounts of nutrients for muscle glucose metabolism.

Keywords: Growth hormone, Insulin, Insulin-like growth factor 1, Exercise. 


\section{INTRODUCTION}

Overweight and obesity are among the major issues of the 21 st century. Obesity is one of the most important risk factors of cardiovascular disease, diabetes, skeletal abnormalities, respiratory and metabolic disorders, cancer, and psychosocial disorders (1). Atherosclerosis is the most important cause of coronary artery disease (2). Genetic, hormonal, metabolic and behavioral factors are involved in development of obesity (3).

Hormones are important factors that affect all body functions (4). Exercise induces considerable changes in the level of some hormones compared to rest period (5). Exercise training increases body demands and causes extensive physiological changes. Therefore, evaluating the physiological events during exercise and adaptation to physical demands is of great importance (6).

Growth hormone (GH) is a non-tropic hormone secreted from the anterior lobe of the pituitary gland that increases muscle growth and hypertrophy by facilitating the transfer of amino acids into the cells. This hormone can exert these effects through production of an intermediate protein in the liver and other cells, known as insulin-like growth factor-1 (IGF-1) or somatomedin C (7). Obese individuals have lower serum concentration of GH and significantly reduced GH secretion, which may present as abdominal fat and increased fat mass (8). The level of plasma GH can influence the amount of plasma free fatty acids. The secretion of GH declines with age, resulting in reduced $\beta$-oxidation of lipids and metabolism of free plasma fatty acids. This increases the amount of insoluble fats such as cholesterol and the deposition of these substances in the arterial wall, ultimately leading to the development of atherosclerosis (9).

IGF-1 is a polypeptide hormone with an amino acid sequence similar to that of proinsulin. The hormone exerts strong growth-promoting effects on muscles and bones and plays a crucial role in growth and metabolism (10). There is a regulatory feedback relationship between GH and IGF-1 where GH secretion increases the hepatic production of IGF-1. Moreover, insulin levels can affect IGFbinding protein 1 (IGFBP1) levels and contribute to the regulation of IGF-1 availability to tissues (11). There may be a correlation between serum IGF-1 levels and increased carotid intima-media thickness and atherosclerosis (12). In this regard, a study demonstrated a reduction in vascular inflammatory responses, systemic vascular oxidative stress and progression of atherosclerotic plaques in experimental mice (13). Decrease in IGF-1 levels or increase in IGF-BP3 protein can reduce the risk of breast cancer and colon cancer in women (5). It has been shown that aerobic exercise can increase level of anabolic hormones such as $\mathrm{GH}$ and IGF-1 in women. Dysfunction of these hormones may result in an increase in fat mass and in a progressive decline in muscle mass $(14,15)$.

As an anabolic hormone, insulin plays an important role in nutrients entry to the cells. In absence of insulin, the transfer of glucose and fatty acids into myocytes is not possible (16). Deficiency or reduction of insulin is associated with development of diabetes. Obese individuals have reduced sensitivity to insulin, thus the pancreas of these individuals should release more insulin to lower plasma glucose (17).

Reduced insulin level increases lipolysis and hepatic glycogenolysis, and inhibits glycogen synthesis. In addition, reduction in insulin secretion increases blood glucose levels (18). Although several studies have been conducted on hormonal responses to exercise activities, especially to resistance training, results of studies on physiological and hormonal responses to aerobic exercise in obese, middleaged women are limited and contradictory. Therefore, the aim of this study was to investigate effects of a six-month aerobic exercise program on serum levels of GH, IGF1 and insulin in sedentary middle-aged women.

\section{MATERIAL AND METHODS}

In this quasi-experimental study, 15 inactive, obese [body mass index (BMI) >30] women aged 37-47 years were selected from employees of the Ferdowsi University in Mashhad (Iran), via purposive and available sampling. Exclusion criteria included drug use, menopause, smoking, and participation in a training program within the last six months. The participants were randomly divided into an experimental group $(\mathrm{n}=10)$ and a control $(n=5)$ group. Before the start of training sessions, information and characteristics of the subjects including age, gender, medical 
records, blood pressure, heart rate, and cardiovascular fitness were recorded. Written consent was taken from all participants. Anthropometric characteristics such as height, weight and BMI of each subject were measured and recorded. After completion of questionnaires and examinations, the subjects participated in a briefing before the start of the protocol. The variables were measured by collecting venous blood samples $(7 \mathrm{ml})$ from the left hand of each subject in seating position, 48 hours before the first training session (pretest) and 48 hours after the last training session (after six months of training).

The subjects performed 60 minutes of aerobic exercise, three sessions a week, for six months. The training protocol included slow walking and running, aerobic exercise at constant intensity and $55-65 \%$ of heart rate reserve. The exercise intensity was controlled with a heart rate monitor (Polar, Finland). The control group did not perform any exercise. Insulin level was measured with double-antibody radioimmunoassay using DRG ELISA kits. $\mathrm{GH}$ level were measured using DiaSorin kits and an ELISA reader (USA) with a sensitivity of $0.2 \mathrm{ng} / \mathrm{ml}$. IGF-1 level was measured by chemiluminescence immunoassay using an calculating the mean and standard deviation (SD) for each variable, the Shapiro-Wilk test and the Levene's test were used to assess normal distribution of data and homogeneity of variance, respectively. Independent and dependent t-tests were used to compare between-group and within-group differences at significance of 0.05 . All statistical analyses were performed using the SPSS software (version 18).

\section{RESULTS}

Table 1 shows the characteristics of the subjects in both study groups. Results of the dependent t-test showed that IGF-1 and insulin levels reduced significantly after the six months of aerobic training $(\mathrm{P}<0.05)$. Although $\mathrm{GH}$ increased in the training group, this increase was not statistically significant (Table 2). Results of the independent t-test revealed a significant difference in the insulin level between the two groups, but there was no significant difference in terms of GH and IGF1 levels (Table 3).

Table 1- Characteristics of the participants in the training and control groups

\begin{tabular}{ccc}
\hline Variable & Training group & Control group \\
\hline Height $(\mathbf{c m})$ & $\mathbf{1 5 6 . 0 0} \pm 5 / 033$ & $\mathbf{1 5 7 . 0 0} \pm \mathbf{3 . 6 0 6}$ \\
Weight $(\mathrm{Kg})$ & $\mathbf{8 0 . 5 3} \pm 9.224$ & $\mathbf{7 7 . 7 8 0} \pm 7 / 074$ \\
Age $(\mathrm{year})$ & $\mathbf{4 1 . 7 0} \pm \mathbf{3 . 1 9 8}$ & $\mathbf{4 3 . 4 0} \pm \mathbf{1 . 5 1}$ \\
BMI $\left(\mathrm{Kg} / \mathrm{m}^{2}\right)$ & $\mathbf{3 1 . 7} \pm \mathbf{5 . 4}$ & $\mathbf{3 0 . 8} \pm 6.3$ \\
Data are shown as mean \pm SD & &
\end{tabular}

Table 2- Mean \pm SD of GH. IGF-1and insulin levels in the training groun

\begin{tabular}{cccc}
\hline Index & Pretest & Posttest & P-value \\
\hline GH $(\mathbf{n g} / \mathbf{m l})$ & $\mathbf{8 . 1 8} \pm \mathbf{2 . 0 0 2}$ & $\mathbf{8 . 2 3} \pm \mathbf{2 . 2 9}$ & $\mathbf{0 . 9 2 7}$ \\
IGF-1 $(\mathbf{n g} / \mathbf{m l})$ & $\mathbf{1 9 2 . 8} \pm \mathbf{2 2 . 6 9}$ & $\mathbf{1 7 8 . 4} \pm \mathbf{2 5 . 3 5}$ & $* 0.035$ \\
Insulin $(\mathbf{m I U} / \mathbf{m l})$ & $9.17 \pm \mathbf{2 . 7 1}$ & $7.63 \pm \mathbf{1 . 7 8}$ & ${ }^{0.03}$ \\
\hline
\end{tabular}

Table 3-Comparison of posttest values of GH, IGF-1 and insulin between the training and the control group

\begin{tabular}{cccc}
\hline Index & Control group & Training group & P-value \\
\hline GH $(\mathbf{n g} / \mathrm{ml})$ & $\mathbf{8 . 8} \pm \mathbf{2 . 2 3 9}$ & $\mathbf{8 . 2 3} \pm \mathbf{2 . 2 9 3}$ & $\mathbf{0 . 6 5 5}$ \\
IGF-1 $(\mathbf{n g} / \mathrm{ml})$ & $\mathbf{1 9 6 . 4} \pm \mathbf{8 . 5 0 2}$ & $\mathbf{1 7 8 . 4} \pm \mathbf{2 5 . 3 5}$ & $\mathbf{0 . 1 5 2}$ \\
Insulin $(\mathbf{m I U} / \mathrm{ml})$ & $\mathbf{1 1 . 4 6} \pm \mathbf{3 . 1 2 3}$ & $\mathbf{7 . 6 3} \pm \mathbf{1 . 7 8}$ & ${ }^{0.009}$ \\
\hline
\end{tabular}

\section{DISCUSSION}

The six-month aerobic training program resulted in an insignificant increase in the $\mathrm{GH}$ level. There was no significant difference between the two groups in terms of GH level. Evidence demonstrates that $\mathrm{GH}$ response to submaximal exercise depends on the exercise intensity. The threshold of growth hormone response is approximately $60-80 \%$ of the maximal oxygen uptake $\left(\mathrm{VO}_{2 \max }\right)$. Performing exercise for sufficient time and at moderate intensity does not affect the GH level. Ultimately, the exercise-induced increase in $\mathrm{GH}$ synthesis relies on the physical fitness of the individual (19). On the other hand, $\mathrm{GH}$ release is regulated by growth hormone releasing hormone; a neuropeptide secreted by the hypothalamus (20). Since sedentary women have low physical fitness, this 
intensity of exercise leads to fatigue, which is accompanied with lactic acid accumulation. This induces GH secretion and stimulates metabolic receptors and transmission of neural signals to the central nervous system and hypothalamus, subsequently resulting in $\mathrm{GH}$ secretion from the anterior pituitary gland (21, 22). Another factor involved in the GH release and partial increase in $\mathrm{GH}$ values could be the increase in sympathetic nervous system activity (23). Overall, the GH response to exercise is more notable in women, which may be attributed to the estrogen level or the low physical fitness of people with high stress during exercise (24). In this regard, studies have shown that 12 weeks of aerobic exercise (three sessions per week and at various intensities) have no significant effect on GH levels of 15 45-year-old men (25). It has also been reported that 16 weeks of 30-minute submaximal aerobic training at $70 \% \mathrm{VO}_{2 \max }$ have no significant effect on the level of anabolic hormones, such as GH (26). In a study, 12 weeks of aerobic and combination exercise training consisted of walking and resistance training with $50-70 \%$ of onerepetition maximum significantly increased GH level in elderly women (50-65 years old) (14). It has also been shown that eight weeks of aerobic training at $35-60 \%$ of the target heart rate caused a significant increase in GH level of elderly women (27). Based on the results of previous studies, it can be concluded that $\mathrm{GH}$ response is more influenced by the intensity and duration of trainings, the type of exercise training, the physical fitness of individuals, and time of blood sampling (14, 25-27). The most effective exercise programs not only should meet the exercise goals, but also stimulate secretion of hormones involved in anabolism (28).

The results of this study showed that the six months of aerobic training significantly reduced the IGF-1 level. In line with this finding, a study reported that six months of aerobic exercise at $55-65 \%$ of heart rate reserve significantly reduced IGF-1 levels in 19 inactive middle-aged women $(24,29)$. Serum IGF-1 concentrations are influenced by various physiological factors, and $\mathrm{GH}$ is the most important determinant of IGF-1 synthesis in the liver (30). Since reduction in serum IGF-1 concentrations in response to exercise could also be due to a reduction in hepatic IGF-1 release in response to $\mathrm{GH}$, the reduced
IGF-1 concentrations in our study can be attributed to the lack of a significant increase in the $\mathrm{GH}$ levels, as $\mathrm{GH}$ only increases in response to intense training $(31,32)$. The incidence of colon cancer is thought to be closely related to changes in the IGF-1 concentration, in a way that individuals with high IGF-1 concentrations are at 2.5-fold higher risk of developing colon cancer $(33,34)$. In general, the mechanisms involved in the secretion and control of GH and IGF-1 include growth hormone releasing hormone secretion from the hypothalamic nuclei, secretion of $\mathrm{GH}$ from the anterior pituitary gland, and GHinduced IGF-1 secretion from the liver. Proteins bound to IGF-1 are considered as factors that indirectly affect musculoskeletal growth. These proteins reduce concentrations of free IGF-1 and subsequently reduce their anabolic effects, but they also increase IGF-1 longevity by preventing its breakdown (35). We also found that the six-month aerobic exercise program could significantly reduce insulin levels. Strong evidence supports the role of GH/IGF-1 axis in maintaining normal glucose homeostasis, and the association of insulin with increased IGF-1 synthesis and activity (36). Some myogenic effects of insulin may be generated through interaction with IGF-1 receptors (37). Thus, the decreased level of insulin in our study can be attributed to the reduction in IGF-1 levels. Reduced physical activity with age may partially lead to a decrease in anabolic hormones, indicating the effectiveness of increased physical activity for compensating the reduction of hormones (38). In addition, insufficient insulin secretion and the development of insulin resistance can lead to diabetes mellitus. Previous studies reported a significant decrease in serum insulin levels following several weeks of aerobic training $(39,40)$. Moreover, a study reported that eight weeks of aerobic training in obese women does not cause a significant decrease in insulin levels (41). Other studies demonstrated lack of a significant change in serum insulin levels of obese women following several months of low-intensity aerobic exercise, which might be associated with insufficient intensity of walking exercises (42).

\section{CONCLUSION}

We demonstrated that exercise at moderate (submaximal) intensity significantly affects insulin and IGF-1 levels, but has no 
significant effect on GH levels. This hormonal response to physical activity could be influenced by the intensity and duration of exercise. It can be concluded that the six-week aerobic training program used in the study has positive impact on metabolism.

\section{REFERENCE}

1. Tokmakidis SV, Kontantinos A. Training and detraining effects of a combined strength and aerobic exercise program on blood lipids in patients with coronary disease. J Cordiopulmonery Reh. 2003; 23(3): 193-200.]

2. Jayachandran M, Okano H. Sex - specific changes in platelet aggregation and secretion with sexual maturity in pigs. J Appl phsyiol. 2004; 97(4): 1445-1452.

3. Walls HL, Peeters A, Son PT, Quang NN, Hoai NT, Loi dD, et al. Prevalence of underweight, overweight and obesity in urban Hanoi, Vietnam. Asia Pac J Clin Nutr. 2009; 18(2): 234-9.

4. William DM, Frank IK \& Victor LK. Exercise Physiology: Energy, Nutrtion and Human Performance. Trans by Khaledan A. Tehran: SAMT. 2008; P. 565-6. [Persian]

5. bagheri M, Bambaeichi E, Esfarjani F, Sattar M. The Effect of 8 Weeks of Water Training on Growth Hormone and Insulin-Like Growth Factor in Children. journal of sport biosciences. 2013;14(4): 21-36. [Persian]

6. Buyukyazi G, Karamizrak S, Islegen C. Effects of continuous and interval running training on serum growth and cortisol hormones in junior male basketball players. Acta Physiol Hing. 2003; 90(1): 69-79.

7. Baechle TR, Earle R. Essentials of strength training and conditioning. $2^{\text {nd }}$ ed. Champaign, IL: Human Kinetics. 1994.

8. Matinhomaee H, Moradi F, Azarbayjani MA, Peeri M. Growth Hormone, Insulin Resistance Index, Lipid Profile, and Cardiorespiratory Function in Obese and Lean Inactive Young Men: Correlations with Plasma Acylated Ghrelin Levels. Knowledge \& Health. 2011; 6(2):18-25. [Persian]

9. Higashi Y, Sukhanov S, Anwar A, Shai S, Delafontaine P. Aging, atherosclerosis, and IGF-1. J Gerontol A Biol Sci Med Sci. 2012; 67(6): 626-39. doi: 10.1093/gerona/gls 102 .

10. Roith DL, Bondy C, Yakar S, Liu JL, Butler A. The somatomedin hypothesis. Endocr Rev. 2001; 22 (1): 5374.

11.Voskail DW, Vrielling A, Van't Veer LJ, Kampman E, Rookus MA. The insulin-like growth factor system in cancer prevention: potential of dietary intervention strategies. Cancer Epidemiol Biomarkers. 2005;14(1):195-203.

12. Kawachi S, Takeda N, Sasaki A, Kokubo Y, Takami $\mathrm{K}$, Sarui H, et al. Circulating Insulin-like growth factor-1 and Insulin-like growth factor binding protein-3 are associated with early carotid atherosclerosis. Arterioscler Thromb Vasc Biol. 2005; 25(3): 617-21.

\section{ACKNOWLEDGMENTS}

The authors would like to thank all those who have contributed to this study.

\section{CONFLICT OF INTEREST}

The authors declare that there is no conflict of interest.

13. Sukhanov S, Higashi Y, Shai S, Vaughn C, Mohler J, $\mathrm{Li} \mathrm{Y}$, et al. IGF-1 reduces inflammatoy responses, suppresses oxidative stress, and decreases Atherosclerosis progression in Apo E deficient mice. Arteioscler Thromb Vasc Biol. 2007; 27(12): 2684- 90.

14. Seo DI, Jun TW, Park KS, Chang H, So WY, Song W. 12 weeks of combined exercise is better than aerobic exercise for increasing growth hormone in middle-aged women. Int J Sport Nutr Exerc Metab. 2010; 20(1): 21-6.

15. Copeland JL, Consitt LA, Tremblay MS. Hormonal responses to endurance and resistance exercise in females aged 19-69 years. J Gerontol A Biol Sci Med Sci .2002; 57(4): B158-B165.

16. Abaassi Daluee A, Ghanbari Niaki A, Fathi R, Hedayati M. The Effect of a Single Session Aerobic Exercise on Plasma Ghrelin, GH, Insulin and Cortisol in Non-Athlete University Male Students. Iranian Journal of Endocrinology and Metabolism. 2011; 13(2): 197-201. [Persian]

17. Hughes K, Aw T-C, Kuperan P, Choo M.Central obesity, insulin resistance, syndrome $X$, lipoprotein (a), and cardiovascular risk in Indians, Malays, and Chinese in Singapore. J Epidemiol Community Health. 1997; 51(4): 394-9.

18. Mirdar S, Safai-Kenari A, Rohi h, Abbasian S. Effect of sprint training on the response and adaptation of enzymes, metabolites and hormones of healthy men. Medical Journal of Mashhad University of Medical Sciences. 2014; 56(6): 330-339. [Persian]

19. Viru A, Viru M. Biochemical monitoring of sport training. UK: Human Kinetics. 2001; 94-97.

20. Godfrey RJ, Madgwick Z, Whyte GP. The exerciseinduced growth hormone response in athletes. Sports Med. 2003; 33(8): 599-613.

21. Manshouri M, Ghanbari-Niaki A, Kraemer RR, Shemshaki A. Time course alterations of plasma obestatin and growth hormone levels in response to short-term anaerobic exercise training in college women. Appl Physiol Nutr Metab. 2008; 33(6): 1246-9. doi: 10.1139/H08-098.

22. Chwalbinska-Moneta J, Kruk B, Nazar K, Krzeminski K, Kaciuba-Uscilko H, Ziemba A. Early effects of short-term endurance training on hormonal responses to graded exercise. J Physiol Pharmacol. 2005; 56(1): 87-99.

23. Cao ZB, Maeda A, Shima N, Kurata H, Nishizono H. The effect of a 12-week combined exercise intervention program on physical performance and gait kinematics in communitydwelling elderly women. J Physiol Anthropol 2007; 26(3): 325-32. 
24. Bijeh N, Hejazi K. The effect of a six-month aerobic exercise on levels of $G H, I G F-1$ and $G H / I G F-1$ ratio serum in sedentary middle-aged women. J Shahid Sadoughi Univ Med Sci 2013; 21(4): 415-27. [Persian]

25. Khorshidi D, Assarzadeh M, Akbarpour Ben M, Azizbeigi K, Abedi B, Ezadi M. The effect of a period of selective aerobic exercise on serum level of leptin and some hormones in obese men. Ann Biolog Res. 2012; 3(3): 1415-23. [Persian]

26. Lovell D, Cuneo R, Wallace J, McLellan C. The hormonal response of older men to sub-maximum aerobic exercise: the effect of training and detraining. Steroids. 2012; 77(5): 413-8. doi: 10.1016/j.steroids.2011.12.022.

27. Tofighi A, Jalali Dehkordi A, Tartibian B, Fatholahi Shourabeh F, sinaei M. Effects of aerobic, resistance, and concurrent training on secretion of growth hormone and insulin-like growth factor-1 in elderly women. $\mathrm{J}$ Isfahan Med School. 2012; 30(184): 427-38. [Persian]

28.Kargarfard Mehdi, Amiri Ehsan, Moradian Keyvan. The Comparison of four Resistance Training Protocols on Level of Human Growth Hormone Secretion in Beginner Male Athletes. Journal of Isfahan Medical School. 2010; 28(108): 327-338. [Persian]

29.Nishida Y, Matsubara T, Tobina T, Shindo M, Tokuyama K, Tanaka K, et al. Effect of low-intensity aerobic exercise on insulin-like growth factor-i and insulin-like growth factor-binding proteins in healthy men. Int J Endocr. 2010; 1(1): 1-8.

30-Dannis L, Kasper A, Braunwald E, Fauci A. Harrison's Principles of Internal Medicine. $16^{\text {th }}$ ed. New York: Mc Graw-Hill Companies: 2005.

31. Schwarz AJ, Brasel JA, Hintz RL, Mohan S, Cooper DM. Acute effect of brief low- and highintensity lexercise on circulating IGF-1, II, and IGF binding protein-3 and its proteolysis in young healthy men. J Clin Endocrinol Metab .1996; 81(10): 3492-7.

32. Cappon J, Brasel JA, Mohan S, Cooper DM. Effect of brief exercise on circulating insulin-like growth factor-I. J Appl Physiol. 1994; 76(6): 2490-6.
33. Pechlivanis S, Pardini B, Bermejo JL, Wagner K, Naccarati A, Vodickova L, et al. Insulin pathway related genes and risk of colorectal cancer. Endocr Relat Cancer. 2007; 14(3): 733-40.

34. Denduluri SK, Idowu O, Wang Z, Liao Z, Yan Z, Mohammed MK, et al. Insulin-like growth factor (IGF) signaling in tumorigenesis and the development of cancer drug resistance. Genes \& Diseases. 2015; 2(1): 13-25.

35-Di Luigi L, Guidetti L. IGF-I, IGFBP2, and-3: do they have a role in detecting $r$ GH abouse in trained men? Med Sci Sports Exerc. 2002; 34(8): 1270-8.

36.Clemmons DR. Role of insulin-like growth factor in maintaining normal glucose homeostasis. Horm Res. 2004; 62(1): 77- 82.

37.Kaaks R, Lukanova A. Energy balance and cancer: the role of insulin and insulin-like growth factor-I. Proc Nutr Soc. 2001; 60(1): 91-106.

38.Copeland JL. Anabolic hormones in aging women: effects of supplementation vs. physical activity. Can J Appl Physiol. 2004; 29(1): 76-89.

39.Taghian F, Zolfaghary M. Effect of 12 week aerobic exercise on the obestatin level in obese women. J Jahrom Univ Med Sci .2014; 11(4): 1-8.[Persian]

40.Habibzadeh N, Rahmani-Nia F, Daneshmandi H. The Effect of Walking Exercise on the Amount of Fat Mass and Serum Insulinin Obese Girls. Journal of zanjan university of medical sciences and health services winter. 2011; 18(73): 18-25. [Persian]

41.Abdi Keykanlo N, Rohani H, Asari F. Effects of 8 weeks aerobic training on body composition and plasma levels of insulin- like growth factor-1 and insulin-like growth factor binding protein-3 in obese women. koomesh. 2014; 15 (3): 302-309. [Persian]

42. Swartz AM, Strath SJ, Bassett DR, Moore JB, Redwine BA, Groër M, et al. Increasing daily walking improves glucose tolerance in overweight women. American Health Foundation and Elsevier Inc. 2003; 37(4): 356-62. 